\title{
Jimeno-Borrero, J. (2020). La compañía de comercio sevillana entre 1747 y 1848. Diputación de Sevilla.
}

\author{
Reseña realizada por: \\ Jesús Fernández Entralgo
}

Magistrado jubilado

DOI: https://doi.org/10.18046/prec.v19.4751

Un conocido periodista escribió, hace ya muchos años, que, dispuesto a escribir un artículo, su primera preocupación era encontrar el título adecuado, que serviría de cebo para el eventual lector. Todo lo demás, con ser importante, vendría por añadidura. Los títulos de los trabajos universitarios, obsesionados sus autores por dar una imagen de sesuda cientificidad, suelen resultar disuasorios para todo aquel que no esté muy interesado en la materia.

Cuando el azar y la amistad pusieron en mis manos el libro de Jesús Jimeno Borrero, me pregunté si, no siendo quien esto escribe cultivador del derecho mercantil y aún menos de su historia, tenía algún sentido su lectura y si hacer su reseña no se tomaría como intolerable pretenciosidad. Me animó comprobar que contaba con el aval de su presentación por el profesor Carlos Petit, de conocido prestigio, y no lo dudé más. Ahora me alegra haber leído el libro, aunque siga convencido de mi falta de competencia para salir airoso del encargo de su autor.

\section{I}

En su prólogo, el prestigioso profesor Carlos Petit pone de manifiesto las razones que, en su opinión, justifican el análisis de las compañías sevillanas en el período histórico acotado. 


\section{II}

El marco normativo general remite a las Ordenanzas de Bilbao de 1737, diez años antes de la constitución de la Real Compañía de San Fernando, fecha de partida del estudio de Jesús Jimeno; un derecho corporativo y local de los mercaderes de esa villa cantábrica, compendio del ius mercatorum de la época, de los usos y las costumbres de los comerciantes, cuya fuerza expansiva no impidió el desarrollo de prácticas locales e intentos de regulación normativa, primero mediante ordenanzas (sirvan de ejemplo las de Sevilla, Cádiz y Málaga, presentes en la obra) y, finalmente, alentado por la promulgación del Code de Commerce francés de 1807, el Código de Comercio de 1829 (deudor del esfuerzo personal de Pedro Sáinz de Andino), que abre una nueva época, especialmente en materia de sociedades, que culmina con la irrupción de las sociedades anónimas, reguladas por su ley especial de 1848 .

Fueron cien años de profundas transformaciones que-se lee en la introduccióntanto afectaron a Sevilla, "gran metrópoli comercial con América, ciudad eminentemente agraria, tras el traslado a Cádiz del Consulado de Cargadores a Indias" (p. 21); que ve luego "el inicio de grandes obras, tras las invasiones napoleónicas y la posterior desamortización de los bienes municipales" (p. 21).

El mismo Jesús Jimeno reconoce que optó por centrar su estudio de la bibliografía del período estudiado en la primera mitad del siglo XIX, y muy especialmente a partir de los códigos francés de 1807 y español de 1829, remitiendo a los trabajos anteriores de los profesores Petit y Martínez Gijón.

La obra se divide en ocho capítulos, precedidos de una introducción y seguidos de una relación alfabética de documentos consultados, de un interesantísimo apéndice documental por sociedades y de un abundante índice bibliográfico.

1. El primer capítulo está dedicado al concepto de compañía de comercio y a los requisitos formales del contrato de sociedad.

Se estudia, ante todo, el concepto en las ordenanzas consulares, que proporcionan ya una definición de la compañía en estrictos términos mercantiles, centrado en la intervención de unos profesionales del comercio (los mercatores) y en la consecución de un lucro como fin de su actividad. 
El concepto de contrato de sociedad que manejan los comerciantes sevillanos es eminentemente consensual. El consentimiento ha de ser previo a la formación de la comunidad de bienes sociales, excepción hecha de la continuación de la sociedad por los hijos del comerciante fallecido, cuyo consentimiento ha de ser obviamente posterior a la constitución de aquella, coincidiendo con la aceptación de la herencia.

Reclama además la aportación de un capital o fondo social por los socios, que puede revestir las más variadas fórmulas; y la fijación de un plazo de duración de la compañía, imposibilitando las de carácter vitalicio y las que se agoten en la realización de un único acto negocial, aunque en la práctica sevillana se encuentren excepciones a esta regla general.

Esta estructura nacida del contrato de compañía está en sintonía con los nuevos principios sociales y políticos que desembocaría en los códigos mercantiles de Francia y de España. La transformación "se traduce fundamentalmente en la aportación de tres aspectos: [...] la personalidad jurídica de la sociedad [...], [como] 'ser moral' [...], el sometimiento exclusivo [...] a la ley mercantil y a la vigencia del código en los territorios del estado [...] [y] el acto de comercio como fundamento de la aplicación del derecho mercantil". Los tres son desarrollados pormenorizadamente en las páginas siguientes.

Es interesante leer las páginas dedicadas a una serie de negocios que han funcionado en algún momento como sucedáneos de la compañía mercantil, como el mutuo o la comenda e, incluso, la simple comunidad de bienes o la donación. La imaginación de los mercaderes supo aprovecharlos para conseguir objetivos equivalentes a los de la sociedad propiamente dicha.

Se configura la compañía de comercio como un contexto de confianza que la asienta sobre la affectio societatis y la idea del intuitus personarum, que perviven en el período de la codificación. Lo anterior explica la frecuencia de un sustrato de relaciones familiares que puede comprobarse en las dos compañías sevillanas Calzada y Munilla y Carrasco e hijo.

Al pasar a estudiar los requisitos formales del contrato de compañía, se advierte que, a partir del siglo XVIII, se exige la documentación de la sociedad en forma pública, lo que significa una fractura con la regla de libertad contractual vigente desde las Partidas. El examen de la práctica sevillana revela, no obstante, la subsistencia de la pauta consensualista precedente. La sociedad Villalón/ Pastor puede servir de muestra. 
El Código de 1829 establece la obligación de que los compañeros reduzcan el contrato a escritura pública, cualquiera que sea la forma social elegida. Pero ello no impidió que ocasionalmente (compañía Señores Calzada y Munilla) previeran la posibilidad de tomar algunos acuerdos en forma verbal.

La ausencia de este requisito conduce a soluciones especialmente atentas a la protección de los derechos e intereses de terceros que contrataron con la sociedad, aunque parte de los mercantilistas de la época las vean desfavorablemente. Se añaden a las páginas dedicadas a este tema otras sobre la obligación complementaria de depositar la escritura en el consulado o en el registro público de comercio.

2. El capítulo II de la obra tiene por objeto el análisis de los agentes sociales que constituyeron las compañías sevillanas en el período acotado y la capacidad de aquéllos para la correcta formalización de las sociedades.

Para participar en sociedades de000 naturaleza exclusivamente mercantil, se requería cierta aptitud específica, de modo que ya con anterioridad a la codificación se fijaron algunas incompatibilidades profesionales (tachas legales), como la que afecta a los jueces profesionales, a la que el Código de 1829 agregó la tocante a los clérigos; a los que los mercantilistas posteriores unieron los locos, los fatuos, los sordomudos, los desmemoriados y los declarados pródigos. Contrastaba todo ello con la tendencia del inmediato ámbito comparado a consagrar la libertad del ejercicio del comercio.

El Código de 1829 permitió ejercer el comercio al mayor de veinte años cumplidos, frente a los veinticinco anteriores, pero siempre que hubiera sido 228 emancipado legalmente, tuviera peculio propio, hubiera sido habilitado para la administración de sus bienes con arreglo a las leyes comunes y renunciado al beneficio de restitución in integrum. En todo caso, no podía vender, dar en pago o enajenar sus bienes, por no ser estos actos de comercio en sentido estricto.

La prohibición de comerciar que afectaba a los clérigos desde las Partidas se mantuvo en la primera codificación mercantil. Se discutió si se extendía a la constitución de sociedades. En la práctica sevillana, la actividad mercantil por parte del clero no es totalmente desconocida pero sí residual.

La documentación encontrada en el archivo sevillano no revela la presencia de noble alguno en ninguna sociedad. Contrasta con la constante presencia de miembros del estamento nobiliario en el tráfico gaditano en los tiempos del 
monopolio del comercio de Indias. El desinterés de la nobleza sevillana por el comercio está estrechamente relacionado con su dedicación a la explotación de la tierra.

La incompatibilidad de intereses explica la exclusión de oficiales públicos, salvo que cuenten con una autorización expresa. La casuística sevillana conoce dos sociedades formalizadas por oficiales públicos, ambas anteriores al Código de 1829. Por la misma razón, quedan excluidos los militares, salvo que operen por persona interpuesta, como ocurre en el único caso registrado en la práctica de Sevilla.

El lector seguramente se sorprenderá al saber que se registran casos de sociedades en las que participa un esclavo, siempre con autorización de su amo, al que se le imputan las ganancias y los perjuicios. En la sociedad Gómez/López, el esclavo Santos Gómez tenía derecho a un sexto de las utilidades, destinado al adelantamiento de su manumisión.

Un buen número de mujeres se sirvió de la fórmula jurídica de la compañía para el desarrollo de sus actividades comerciales. También en Sevilla, y no solo las solteras o las viudas. La casuística sevillana reconoce su actividad mercantil en variedad de giros de comercio y diferente cuantificación pecuniaria del capital social. El doctor Jimeno dedica muchas y jugosas páginas al estudio de la actividad mercantil de mujeres emancipadas, de mujeres solteras o viudas y de casadas con licencia marital.

En fin, aunque la participación de extranjeros en el comercio y, consecuentemente, en compañías mercantiles no había sido rara ya en la Edad Media, y aumentó exponencialmente tras el descubrimiento de América, el número de sociedades solemnizadas por extranjeros en Sevilla es menor del que cabía esperar; fenómeno acaso debido a una pluralidad de razones sociales y políticas. Hay un prejuicio contra los comerciantes no españoles, singularmente contra los franceses, acrecentado tras los sucesos revolucionarios a partir de 1789. Ello explica la ausencia de sociedades en los documentos manejados desde 1791 (compañía Sinisergues/Fricu) hasta 1846 (Steinacher y Compañía), ya promulgado el Código, que había tratado de dar un giro aperturista a la inversión extranjera.

El autor dedica especial atención a la comunidad flamenca, a la que pertenecen muchos integrantes de sociedades, aunque hayan castellanizado sus apellidos. 
3. El capítulo III se ocupa de la tipología de la Compañía de Comercio. Se abre con una aproximación a sus diferentes tipos. El predominio absoluto de la sociedad regular colectiva se mantiene - no sin protestas- en las Ordenanzas de Bilbao, pero en las del Consulado de Málaga convivirán con la comanditaria y con la peculiar sociedad pública o corporativa, diseñada para poder recaudar, entre los múltiples accionistas, los caudales suficientes para poder emprender obras públicas, lo que facilitaba a los accionistas la posibilidad de limitar su responsabilidad al fondo que hubiesen desembolsado.

El Código de 1829 (al igual que el proyecto de la Comisión Real) parte de una sola especie de compañía, la colectiva o general, de las que son subclases ("irregulares", en la terminología del proyecto) la en comandita y la anónima.

La práctica mercantil sevillana revela la existencia de una reiterada constitución de la sociedad general, pero no desde la perspectiva de una determinada opción tipológica, sino como la sociedad genérica y auténtica en la que comerciantes, artesanos y productores encuentran la mejor forma de definir los pactos y surtir las oportunas garantías, provenientes de la responsabilidad limitada y las continuas necesidades de crédito. El autor desarrolla un análisis detallado y documentado en esta materia.

En el período analizado, ni en Sevilla ni en Cádiz se descubre la existencia de sociedades comanditarias, salvo una (Agustín Henkes y Compañía, en Sevilla, en 1844) que se califica a sí misma de este modo. Hay otras, escasas, cuya calificación como tal es cuestionable. Buen ejemplo de ellas es la de Manuel Rufo y Compañía, en Sevilla, en 1819. Importa tener en cuenta la inclusión de un socio en la denominación de la compañía y en la gestión social. Las páginas 230 dedicadas al estudio de esta modalidad societaria resultan muy ilustrativas.

Como cabía esperar, se reserva un lugar destacado al estudio de la evolución de la compañía anónima. Comienza por el período anterior a la codificación, con mención especial de la Real Compañía de San Fernando (conexa en cierto modo con el precedente asiento de avería), cuya instauración se produjo en Sevilla, al objeto de reactivar o fortalecer la industria textil y el acceso al comercio con las colonias americanas, entonces vedado por el monopolio gaditano. La Real Compañía se define como un sujeto institucional, más propio de un esquema actual de derecho público. El accionista se adhiere al decreto particular del monarca, donde se establecen rigurosamente los privilegios reales y las reglas de reparto de dividendos, la transferencia de los títulos y el voto en las asambleas. El autor no duda en deshacer equívocos a propósito de la (a su 
juicio equivocadamente denominada) responsabilidad limitada de los accionistas y a la transmisibilidad de las acciones, al parecer condicionada a la autorización de los órganos de gestión social y a la aprobación asamblearia.

Llama la atención sobre la Compañía Seguradora Santísimo Cristo de las Tres Caídas, organizada como sociedad privada por acciones, cuya documentación encontrada en los archivos sevillanos está huérfana del estudio que merece por sus singularidades (que la aproximan a la sociedad anónima en sentido propio), comparada con la realidad mercantil de otras plazas. El doctor Jimeno trata de colmar, siquiera parcialmente, esta laguna.

Como era de esperar, se detiene en el estudio de la compañía anónima o compañía por acciones en la etapa codificadora. Enfatiza el vínculo entre la denominación de la sociedad y su objeto, relacionado con las grandes obras públicas y los vastos negocios comerciales de la revolución industrial, a los que, como expresaba Jean Marie Pardessus, un solo socio no puede hacer frente.

La sociedad anónima gira en torno a su capital, que funciona como límite de la responsabilidad personal de los accionistas, y a su configuración como persona jurídica, en cuanto centro de imputación de derechos, intereses y responsabilidades. Y, consecuentemente, se consagra la transmisibilidad de las acciones y su correspondiente representación en distintas cédulas de créditos.

Reviste gran interés el epígrafe dedicado a las fórmulas asociativas atípicas en la práctica sevillana, como las constituidas exclusivamente para la ejecución de un solo negocio jurídico cuya consumación agota el giro de comercio y origina la disolución de la compañía. Tal es el caso de la Bené/Laranza. La segunda modalidad es aquella en que el objeto perseguido es el acuerdo que permitirá a los compradores y los socios alterar el precio de un determinado producto; algo muy parecido a establecer un monopolio, como ocurre con González de la Bonilla/Merino/Vallejo y con Calero/Carasco/lerenzuelo/Merlo/Vicedo.

4. El capítulo IV trata del capital social como base patrimonial de la sociedad. Por capital social debe entenderse el conjunto de bienes de la sociedad sujeto a valoración económica y que sirve para alcanzar el objeto de comercio y asumir la responsabilidad patrimonial en que pueda incurrir la sociedad.

Aunque se conocen en Sevilla casos de sociedad opera cum opera (propia de un arte u oficio), cuyo fondo está formado desde un principio por la sola industria de los socios (por ejemplo, la Vicedo/Calero/Carrasco/Lerrezuelo, en 1835), tienen un carácter residual. 
La casuística sevillana parte de la común y general determinación del capital social, aunque en algunas sociedades (Alonso/Ximénez) el capital queda indeterminado al tiempo de formalizar el contrato; indeterminación que puede llegar a mantenerse durante toda la vida de la compañía (Morales/Muribe).

Sigue el autor al profesor Petit (en su estudio sobre las compañías bilbaínas) al ocuparse de la titularidad de los bienes aportados en concepto de capital social y de su disposición tras la liquidación de la sociedad. La reserva del bien entregado en concepto de capital domina en la práctica sevillana, aunque no falten casos de división del capital común en proporción con las respectivas aportaciones de los socios (Colarte/Díaz). El doctor Jimeno se extiende largamente sobre estos extremos.

La fijación del fondo común en la escritura de sociedad reviste vital importancia ya en las normas de las ordenanzas. Y tanto las ordenanzas como el Código de Sainz de Andino muestran su preocupación por controlar las posibles detracciones de fondos para gastos. La práctica sevillana acepta su licitud cuando tengan por objeto posibilitar la continuidad de la empresa e, incluso, la supervivencia del socio industrial, previendo una amplia variedad de formas de retirada de sumas del fondo de la compañía. Lo anterior es solo una muestra de la variada temática de este apartado.

Concluye el capítulo con un estudio del momento de la conformación del capital social y del incumplimiento de su aportación por el socio.

5. El capítulo quinto se dedica a la responsabilidad de los socios frente a las deudas sociales.

232 La compañía sevillana distingue entre deudas de la sociedad y aquellas otras provenientes de las relaciones personales de los socios.

El primer Código español de comercio prohibía que los acreedores particulares de un socio sustrajeran de la masa social cantidad alguna para satisfacer sus créditos, debiendo estar a lo que resultara de la liquidación de la compañía, respetando la oportuna prelación de créditos. Las compañías sevillanas distinguieron ambas clases de deudas, fijando o detallando las deudas personales contraídas en el período anterior a la constitución de la sociedad y correlativamente el régimen de responsabilidad. Mientras que otras sociedades detallaban en la escritura las posibles vicisitudes ulteriores y sus posibles consecuencias.

El principio de solidaridad rige la responsabilidad por los negocios rubricados por el administrador social dentro de los límites establecidos en los poderes 
conferidos. La casuística mercantil sevillana muestra un rico compendio de supuestos donde se utiliza la libertad de pactos para modular la responsabilidad de la sociedad por algunos negocios, incluso ilegales (Fernández/Barreda), cuando el administrador se obliga sin la aprobación previa de los capitalistas (Barea/ Escacena) o cuando directamente se excluye de contratar a los restantes socios.

Está muy extendida la idea de que la responsabilidad ilimitada del socio es característica esencial de la sociedad colectiva. A juicio del autor, debería relativizarse e incluso plantear la posibilidad de que los socios, aun asumiendo en el contrato una responsabilidad universal, excluyan algunos bienes de las deudas a las que deban hacer frente con posterioridad. En la práctica sevillana así se hace en el contrato de Señores Calzada y Munilla, ya en 1844.

Los textos codificados y la bibliografía especializada de la época acotada optan por la regla de la responsabilidad de cada socio por la totalidad de lo adeudado por la sociedad, aunque en la práctica sevillana no falten excepciones; así en García y García, donde uno de los asociados asume la totalidad de las deudas a cambio de quedarse con el patrimonio resultante tras la liquidación.

Se estudian a continuación las limitaciones a la responsabilidad solidaria de los socios. La regla de la responsabilidad personal y universal de la compañía general no siempre se cumple, en efecto, en las sevillanas; pero no se puede perder de vista que, en ejercicio de la libertad de pacto, se configuran sociedades de naturaleza difícilmente calificable, como ocurre con la Manuel Rufo y Compañía. En la compañía comanditaria, doctrina y legislación coinciden en establecer una responsabilidad circunscrita a la aportación inicial del socio comanditario.

La compañía por acciones anterior a la etapa de la codificación (modelo Real Compañía) es muy diferente de la que le sigue. La Real Compañía es un sujeto institucional en que el accionista simplemente se incorpora al decreto particular del monarca. No está clara la limitación de responsabilidad de los accionistas en la Real Compañía por acciones, y el análisis del reglamento de la Real Compañía de San Fernando, constituida en Sevilla en 1747, no disipa esa duda, o más bien corrobora la responsabilidad solidaria de los socios. Pero hay otras compañías por acciones -como la Compañía Aseguradora Santísimo Cristo de las Tres Caídas-donde los socios responden en proporción a la acción $\mathrm{o}$ acciones de que respectivamente sean titulares y que es el mismo criterio de reparto de posibles beneficios. 
Las sociedades anónimas, reguladas por los diferentes códigos y por el proyecto de Ordenanzas de Málaga del Consulado de Málaga de 1828, que introduce la llamada "compañía pública corporativa", excluyen la responsabilidad personal de los administradores por los actos realizados en nombre y por cuenta de la sociedad, y la limitan al capital aportado en el momento de su constitución, más los beneficios que hayan podido obtenerse. La "Asociación para construir la nueva Plaza de Sevilla: un teatro cómico y demás edificios que se consideren de utilidad", en 1843, limita la responsabilidad a las aportaciones desembolsadas por los accionistas, pero organiza, además, un complejo sistema de garantías hipotecarias que recae sobre los edificios o casas adquiridas a nombre de la compañía y sobre los que se construyan en el futuro. El autor concluye que el modelo de la Asociación para construir la nueva Plaza de Sevilla supone más bien la combinación de sociedad por acciones y copropiedad de los inmuebles adquiridos en nombre de ella, descrita por Pardessus.

Y concluye el capítulo ocupándose del posible embargo de las acciones y de los bienes e intereses de la compañía, y de la conversión de la responsabilidad de los socios en colectiva.

\section{La administración de la compañía.}

La tipología mayoritaria en la práctica sevillana -la sociedad colectiva- haría predecible una administración social conjunta. Sin embargo, el doctor Jimeno comprueba que el estudio de los documentos disponibles revela la existencia de un elevado número de sociedades cuya gestión se encomienda en exclusiva a un socio.

El autor diferencia tres sistemas de gestión societaria: a) administración 234 encomendada a todos los socios; modelo por defecto, salvo pacto expreso que lo contradiga, la modalidad -en sus variedades disyuntiva- habitual en la práctica sevillana o repartida, mayoritaria en la práctica sevillana; b) administración delegada a uno de ellos o incluso a un tercero (caso -discutido- de la compañía Santísimo Cristo de las Tres Caídas); y c) nombramiento de un codirector, supuesto regulado en el Código de 1829, pero de dudosa utilización en la práctica sevillana. Esto, sin olvidar soluciones que combinan sistemas aparentemente contradictorios entre sí, como la Steinecher y Compañía, mezcla de la conjunta y la disyuntiva.

El título de gestión gira en torno al contrato, ya sea tácito, con gestión solidaria de los socios, expreso contenido en la escritura de constitución o incluso 
como habilitación nominal en un documento independiente, con vigencia diferida a la constitución de la sociedad.

El poder de gestión o administración puede ser irrevocable o admitir causas de revocación, como la extralimitación o el abuso de poderes; y permitir el nombramiento de sustituto en general o en casos predeterminados y ocasionales.

La dimensión deliberativa de la administración (cómo decidir) no parece haber preocupado demasiado. Se admite la delegación en un socio con amplias facultades de gestión, salvo para operaciones de excepcional importancia. También se registran casos de distribución de poderes entre los socios por períodos de tiempo.

Está muy extendida la regla de la unanimidad, indicio del fuerte componente del intuitus personarum. Cabe la aprobación tácita por silencio omisivo de los consocios. El administrador contrata en nombre propio y los socios ratifican posteriormente con su firma la gestión realizada por aquel.

En caso de extralimitación del administrador, la regla general es la vinculación de la sociedad con acción de nivelación entre los socios. En la práctica sevillana se prevé que, en este caso, el gestor asume personalmente la total responsabilidad por el resultado.

Aunque hay leyes y estatutos (así los de la anónima para la construcción de la Plaza Nueva) que admiten la posibilidad de una actividad concurrente del administrador, es regla generalizada la prohibición de que se sirva de la firma comercial y de los fondos de la compañía para negociar en interés propio.

El autor advierte, no obstante, que esta prohibición está muy relacionada con la forma de sociedad (en la práctica sevillana rige para la comanditaria y la anónima, cuya regulación adoptaría el Código de Comercio de 1829) y el objeto social, factor muy importante cuando se trata de sociedad colectiva. El incumplimiento de esta incompatibilidad se sanciona de formas muy diversas, que se estudian con detalle en el apartado correspondiente del capítulo.

7. Ganancias, pérdidas y gastos de la compañía.

El reparto igualitario de las ganancias, independiente del valor del capital respectivamente aportado, es regla en la práctica de Sevilla y de otras plazas, pero también se conoce -con muchas modalidades- el reparto proporcional. Se tienen en cuenta para ponderar la aportación el capital, pero también la experiencia y la dedicación en cada socio. 
Se prohíben las llamadas sociedades leoninas o usurarias, en que todas las ganancias pasan a un solo socio. Se registra un caso -la compañía Gómez/ López- en que así se establece respecto de una socia industrial, que era esclava, para poder comprar su libertad. Cuando se pacta que se devuelva al socio capitalista toda su aportación más parte de las ganancias (García/Gutiérrez, Ramón Torrijos), hay interpretaciones que califican estas sociedades como fachadas de un préstamo remunerado.

En la práctica sevillana es casi unánime la distribución de las pérdidas en función de la participación pactada de las posibles ganancias.

Para el sostenimiento de los gastos, es regla general en Sevilla (aunque caben modulaciones) la creación de un fondo común.

8. Disolución y liquidación de la compañía.

Remata la obra un explicablemente largo capítulo dedicado a esta materia. La disolución puede ser consecuencia de una variedad de causas. La producen, ante todo, tanto la expiración del plazo previsto en el contrato como la consecución del objeto social. De acuerdo con el Código de Sáinz de Andino, la disolución tiene lugar después de un período temporal de liquidación. En los estatutos de la Compañía Suárez/Piñal se prevé la posibilidad de renovación de la sociedad.

Es fundamental lo pactado por los socios. Si han previsto la disolución por transcurso del plazo convenido y la consecución del objeto social, hay opiniones divergentes sobre la prevalencia de una en su función de bloqueo de la invocación de la otra.

Para la admisibilidad de la disolución por renuncia o mutuo disenso es 236 fundamental que concurran buena fe y que no sea a contratiempo, esto es, intempestivamente.

Si se fijó un objeto social, no cabe la disolución antes de conseguido "salvo justa causa", como el incumplimiento de los deberes del socio o la malversación de los fondos sociales.

La autonomía de la voluntad de los que forman la sociedad rige las consecuencias del fallecimiento de uno de ellos, y se registran soluciones muy variadas. La forma de la sociedad tiene gran importancia. En las capitalistas, el fallecimiento de un accionista es escasamente relevante. En la colectiva, se tiende a la disolución, aunque pueda convenirse la reproducción de la compañía entre los sobrevivientes, con dudas si concurre un menor de edad. En la comanditaria, la provoca la muerte del socio industrial. 
Restan como causas de disolución la pérdida del capital y la quiebra de la compañía o de un socio. La doctrina demostró por la primera un interés que se refleja en los contratos, aunque su cuantía sea escasa.

La liquidación de la compañía es un procedimiento de larga duración, que regula el Código de 1829 con clara influencia de Pardessus. Lo abre el nombramiento de los liquidadores, partiendo de que lo son (de acuerdo con los contratos y la legislación codificada), aquellos que habían sido administradores, salvo que los estatutos prevean otra cosa: que lo sea un tercero, un socio (por ejemplo, el sobreviviente en caso de fallecimiento del otro) o un perito o práctico del comercio, siempre que no estén vetados por alguno de los miembros de la sociedad en liquidación.

Prestada la correspondiente garantía por el o los liquidadores, se formará inventario dentro de los quince días siguientes a la disolución de la compañía, según dispone el Código de 1829. Los estatutos suelen guardar silencio sobre este extremo.

Examinadas las cuentas por los liquidadores (aunque sean los antiguos socios), procederán a la conclusión de los negocios pendientes, indicando en ellos que representan a la "sociedad en liquidación". La cuenta final se someterá, en el plazo de quince días, a la aprobación por los socios.

\section{IV}

Con una relación alfabética de documentos, un apéndice documental por sociedad muy interesante y una abundante y actualizada bibliografía, concluye el trabajo del doctor Jimeno.

A medida que recorría sus páginas, me iba encontrando con una materia para mí tan novedosa como amena. Sí, amena. Porque su lectura es fácil, al no verse interrumpida por las muchas y largas notas a pie de página, sobre las que se volverá al repasarlo para poderlas disfrutar mejor. Las referencias a la práctica sevillana, a menudo comparada con otras del entorno geográfico inmediato, alegran un estudio que, en otras manos, hubiera resultado fatigoso.

Huelva, a 2 de abril del 2021. 
